
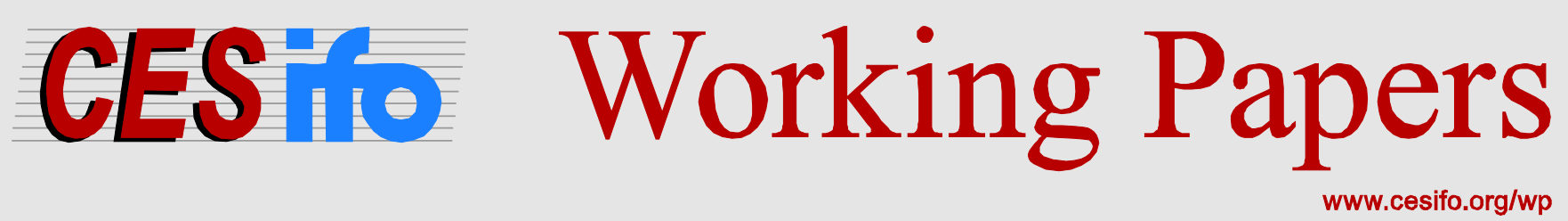

\title{
Tax Competition and the Efficiency of “Benefit-Related” Business Taxes
}

\author{
Elisabeth Gugl \\ George R. Zodrow
}

CESIFO WORKING PAPER NO. 5555

CATEGORY 1: PUBLIC FINANCE

OCTOBER 2015

An electronic version of the paper may be downloaded

- from the SSRN website:

- from the RePEc website:

- from the CESifo website:

WwW.SSRN.com

Www.RePEc.org

www.CESifo-group.org/wp 


\title{
Tax Competition and the Efficiency of "Benefit-Related” Business Taxes
}

\begin{abstract}
We consider a model in which business public services must be financed with either a sourcebased tax on mobile capital, such as a property tax, or a tax on production, such as an originbased VAT and assess which of the two tax instruments is more efficient. In general, both a capital tax and a production tax are inefficient. However, the production tax is efficient if the production function belongs to the knife-edge case between log sub- and log supermodularity with respect to capital and public services (e.g., a Cobb-Douglas production function), while the capital tax results in underprovision of public services in this case. Similarly, if the production function is log submodular with respect to capital and public services (e.g., a CES production function with an elasticity of substitution greater than 1), a production tax is again less inefficient than a capital tax, although both taxes result in underprovision of the public service. Finally, if the production function is log supermodular (e.g., a CES production function with an elasticity of substitution smaller than 1), a production tax results in overprovision of the public service, while the exects of a capital tax - and thus the relative efficiency properties of the two taxes - are theoretically ambiguous.
\end{abstract}

JEL-Code: H410, H420, H210, H110.

Keywords: tax competition, public services provided to business, tax on production vs. tax on capital.

\author{
Elisabeth Gugl \\ Department of Economics \\ University of Victoria \\ P.O. Box 1700 STN-CSC \\ Canada - Victoria, BC, V8W 2 Y2 \\ egugl@uvic.ca
}

\author{
George R. Zodrow \\ Rice University \\ Department of Economics \\ 6100 Main Street, MS-22 \\ USA - Houston TX 77005 \\ zodrow@rice.edu
}

September 2015

We thank Steve Billon, Jed Brewer, Alexander Ebertz, Bill Fox, Timothy Goodspeed, Brad Hackinen, Andreas Haufler, James Hines, Magaret McKeehan, Matt Krzepkowski, David Wildasin, and John Wilson for their comments on earlier versions of the paper. 


\section{Introduction}

In the United States, state and local taxes often take the form of property taxes or corporate income taxes on business capital, which may distort a wide variety of decisions, including those regarding capital accumulation and allocation and the level of public services provided, as stressed in the tax competition literature. In addition, at the state and local level in the United States and at the provincial level in Canada, retail sales taxes often apply tax to business inputs, even though in principle they are supposed to be limited to final consumer goods. In light of this situation, several prominent public finance experts have argued that, in the absence of explicit benefit taxes or user charges, taxes on local production, such as an origin-based value added tax (VAT), are an attractive option (Bird [1], Hines [9]). Such taxes serve as a proxy for user charges - that is, they are relatively efficient "benefitrelated" taxes. In addition, McLure [18] notes that the growing importance of electronic commerce implies that a destination-based VAT is increasingly difficult to administer, providing another argument for an origin-based VAT.

In this paper, we provide what we believe is the first attempt to systematically analyze the assertion that a production-based tax can be viewed as an approximate benefit tax, and is thus preferable to the often-used alternative of a tax on capital. To be sure, there are many papers analyzing the efficiency of capital taxation when firms receive a public service and jurisdictions compete with each other for mobile capital. (See, e.g., Zodrow and Mieszkowski (ZM) [32], Oates and Schwab [21], [22], Noiset [20], Sinn [24], Keen and Marchand [11], Bayindir-Upmann [2], Richter [23], Matsumoto [14], [13], and Dhillon, Wooders and Zissimos [4].) However, these papers focus on the inefficiency of capital taxation alone, and do not consider a tax on local production, or compare such a production tax to a capital tax.

Our results provide some support for the idea that a production-based tax may be viewed as a "benefit-related" tax, although it does not in general substitute perfectly for an explicit user charge. Our analysis reveals that the log modularity properties of the production function play a major role in determining the relative efficiency properties of production-based taxes and capital taxes, an issue that has thus far not been examined in models of interjurisdictional tax competition. In particular, in the special case of a production function that is log modular in capital and the public service

(e.g., a Cobb-Douglas production function), a production tax is effectively a benefit tax, and is thus analogous to a user charge for public services that 
ensures an efficient level of public service provision. In the same vein, if the production function is log submodular in capital and the public service (e.g., a CES production function with an elasticity of substitution greater than 1), a production tax will be inefficient and lead to underprovision of the public service, but it will result in less underprovision and thus be less inefficient than a capital tax. However, although we can show that the production tax leads to overprovision of public services in the case of a log supermodular production function (e.g., a CES production function with an elasticity of substitution smaller than 1), the ambiguity of the effect of a capital tax on public services in this case implies that a comparison of the relative efficiency properties of the two taxes is impossible without further restrictions on the production technology. In a companion paper (Gugl and Zodrow [7]), we provide a wide variety of simulations using the CES production function and find that efficiency gains in the instances in which capital taxes are more efficient are modest.

There is also a vast literature analyzing the efficiency of destination-based vs. origin-based value-added taxes (VATs). In a closed economy, there is no difference between a uniform tax on all consumption and a similar tax on production. In contrast, as economies become increasingly more open, the distinction between a tax on local production and a tax on local consumption becomes important in terms of efficiency (Mintz and Tulkens [19], Kanbur and Keen [10], Lockwood [12], Haufler and Pflüger [8]). In tax competition models in which firms are perfectly competitive, a tax on local consumption such as a destination-based VAT is efficient when countries are too small to affect world prices (Lockwood [12]). Haufler and Pflüger [8] investigate the difference between a destination-based and an origin-based VAT in several settings of international duopoly and find that only the former is efficient when competition between countries is imperfect. Despite the vast literature on different forms of VATs, an origin-based VAT has not been analyzed in models of tax competition where public services are provided to firms. Together with Gugl and Zodrow [7], to the best of our knowledge, this paper is the first to examine this issue.

In the next two sections, we present the model and discuss some wellknown results on capital taxation. Then we derive the equilibrium under a production tax (section 4). Section 5 compares the performance of a capital tax and a production tax. In section 6 we consider alternative tax instruments such as input taxes and analyze them in our model. Section 7 concludes. 


\section{The Model $^{1}$}

Our model follows the ZM [32] framework. ${ }^{2}$ A federation or union consists of $N$ jurisdictions, each with the same number of residents who are immobile across jurisdictions. All residents have identical preferences and endowments. Individuals work where they live, provide a fixed amount of labor, and obtain utility from consumption of an aggregate composite good. The labor supply of each jurisdiction, $L$, is therefore fixed. ${ }^{3}$ People own an equal share of the union's capital stock $\bar{K}$ which is fixed in total supply. Since capital is perfectly mobile across jurisdictions, the after-tax rate of return to capital, $r$, is the same in every jurisdiction.

Each jurisdiction produces a single consumption good, $X$, with a technology characterized by constant returns to scale (CRS) in two private inputs and one public input. Labor and capital are the private inputs in the production of $X$. In addition, the local government provides a fully congestible business public service $B$ that is used directly in the production of the consumption good $X$. We assume throughout the paper that the production function is strictly concave in capital and the public service. The consumption good is assumed to be tradable and is taken as the numeraire.The government can costlessly transform the consumption good into the public service, so its unit cost is also equal to $1 .^{4}$ We assume that the number of firms is fixed in each jurisdiction (or equivalently there is a single representative firm) and focus therefore on the aggregate production function in each jurisdiction given by ${ }^{5}$

$$
X=F(L, K, B)
$$

\footnotetext{
${ }^{1} \mathrm{Gugl}$ and Zodrow [7] provide further discussion of the assumptions in the model.

${ }^{2}$ See also Wilson [27]. For review of the general tax competition literature, see Wilson [28], Wilson and Wildasin [29], and Zodrow [30], [31].

${ }^{3}$ The fixed factor can also be thought of as a combination of labor and land, as assumed in Zodrow and Mieszkowski (ZM) [32].

${ }^{4}$ We follow most of the literature in assuming constant marginal costs for the public service (Oates and Schwab [21], [22], Sinn [24], Bayindir-Upmann [2], Keen and Marchand [11], Richter [23], and Matsumoto [14]). Two alternative approaches, which Matsomoto [14] points out are equivalent, would be to assume either an imperfectly congestible public input and a constant marginal cost of producing that public input, or a perfectly congestible public input (i.e., our publicly provided private service) and decreasing marginal costs of producing the public service.

${ }^{5}$ See e.g. Zodrow and Mieszkowski [32], Bayindir-Upmann [2], Keen and Marchand [11], Dhillon et al. [4] for the same assumption.
} 
where

$$
\begin{aligned}
F(0,0,0) & =0 \\
F_{L} & >0, F_{K}>0, F_{B}>0 \\
F_{K B} & >0, F_{K L}>0, F_{B L}>0, F_{i i}<0 .
\end{aligned}
$$

for $i=L, K, B{ }^{6}$ For a given $L>0$, the second-order-derivative matrix of $F(K, B)$ is assumed to be negative definite for $(K, B)>0 .^{7}$

We consider two tax scenarios. Under the capital tax scenario, all jurisdictions must use a tax on capital $(\tau)$ to finance provision of the business public service. Thus each jurisdiction is subject to a balanced budget constraint,

$$
\tau K=B
$$

Under the alternative production tax scenario, all jurisdictions must use a production tax $(t)$ to finance their business public services

$$
t X=B
$$

In both cases, we assume that the local taxing jurisdiction is a small open economy, with local governments choosing the various tax instruments available to maximize the income of their immobile residents, taking as given the policies of all competing jurisdictions, the union-wide return on capital, and the price of the tradable composite consumption good. Under the capital tax scenario, the total income of residents $I_{C T}$ equals the sum of their capital income from union-wide investment and firm value added (labour income plus profit from local firms $\left.{ }^{8}\right)$.

$$
I_{C T}=r \bar{K} / N+[F(L, K, B)-(r+\tau) K] .
$$

The amount of capital in a jurisdiction is determined by firms' profit maximizing behavior, taking the level of public services and various taxes in the

\footnotetext{
${ }^{6}$ As in the majority of the literature, we assume complementarity between capital and the public service (but not fixed proportions), as we assume a strictly positive crossderivative between capital and the public service in the production function (e.g., Zodrow and Mieszkowski [32], Bayindir-Upmann [2], Keen and Marchand [11], Feehan and Matsumoto [5], Matsumoto [14], [15], [13], and Dhillon et al. [4]).

${ }^{7}$ Negative definiteness implies strict concavity of $F(K, B)$.

${ }^{8}$ There is a possibility for local firms to make profits if the public service is provided to them and they do not bear the full cost of the public service.
} 
jurisdiction as given. Under the production tax scenario, total income of residents $I_{P T}$ equals the sum of their capital income from union-wide investment and total net local production minus capital production costs

$$
I_{P T}=r \bar{K} / N+[(1-t) F(L, K, B)-r K] .
$$

Note that our analysis is short run in the sense that it is possible that perfectly competitive firms will make positive economic profits as they do not have to pay for $B$ directly, e.g., in the form of user charges.

\section{$2.1 \quad$ Efficiency}

Given that $B$ is a publicly provided private good, it is optimal to charge user fees. Since labor supply is fixed we suppress $L$ in the following mathematical exposition. With user fees and fixed $L$, firms maximize profit by

$$
\max _{B, K} F(K, B)-B-r K
$$

The firms' profit maximizing conditions are

$$
\begin{aligned}
& F_{K}(K, B)=r \\
& F_{B}(K, B)=1 .
\end{aligned}
$$

These conditions are necessary and sufficient to determine a unique optimum since $F(K, B)$ is assumed to be strictly concave. Note that assuming increasing returns to scale in $(K, B)$ would rule out the existence of an interior solution even in the case of user charges, and assuming CRS in $(K, B)$ would not lead to a unique interior solution. Thus, in order to get a solution in which the efficient amount of the public service is uniquely determined by $F_{B}=1$, we must assume that the production function is at least locally strictly concave in $(K, B)$ for all $(K, B)>>(\underline{K}, \underline{B})$ for some $\infty>>(\underline{K}, \underline{B}) \geq 0$. See Dhillon et al. [4].

\section{Capital Tax}

Capital taxes have been analyzed in the ZM framework by many authors. ${ }^{9}$ We repeat the analysis here in order to compare the results with the capital

\footnotetext{
${ }^{9}$ For a detailed literature review see Gugl and Zodrow [7].
} 
tax to those with a production tax. Suppose that local governments impose a tax on capital at rate $\tau$. In this case, total resident income is

$$
I_{C T}=r \bar{K} / N+[F(K, \tau K)-(r+\tau) K] .
$$

In calculating its optimal level of taxation, the local government must predict how the demand for capital in the jurisdiction changes as the tax rate $\tau$ is increased, assuming that other jurisdictions do not respond. Differentiating (5) and (9) with respect to $K$ and $\tau$ yields the response of capital to an increase in the capital tax

$$
\phi \equiv-\frac{d K}{d \tau}=-\frac{1-F_{K B} K}{F_{K K}+F_{K B} \tau} .
$$

To determine the sign of $\phi$, note that

Property 1 A proportional increase in $B$ and $K$ will cause $F_{K}$ and $F_{B}$, respectively to decrease, i.e. $B F_{B K}+K F_{K K}<0, K F_{B K}+B F_{B B}<0 .{ }^{10}$

This follows from our assumption that the Hessian of $F(K, B)$ is negative definite and from CRS in production of the consumption good.

Lemma 1 The denominator of $\phi$, given by $F_{K K}+F_{K B} \tau$, is negative.

The proof of Lemma 1, given in the appendix, depends only on property 1 and the assumption of budget balance. Lemma 1 coincides with ZM's stability assumption ( [32], equation 17) and Dhillon et al. [4] show that this assumption is a necessary condition for the existence of a capital tax equilibrium. Given this condition, the perceived change in capital in response to an increase in $\tau$ depends on the sign of $\left(1-F_{K B} K\right)$. This expression measures from the firms' perspective the net impact of an increase in the capital tax rate, reflecting the cost of an increase in the marginal cost of capital, given by 1 , and the benefit of the associated increase in $B$ on the marginal productivity of capital, given by $F_{K B} K$. If the marginal cost and marginal benefit from the firm's perspective are not equal, firms will lower their demand for capital if $1>F_{K B} K$, and increase it if $1<F_{K B} K$.

\footnotetext{
${ }^{10}$ Property 1 would also hold if $F(L, K, B)$ is homothetic in $(K, B)$ instead of assuming CRS in all factors.
} 
With local jurisdictions choosing $\tau$ to maximize the income of their residents (11), the first order condition is

$$
K\left(F_{B}-1\right)-F_{B} \tau \phi=0
$$

and the optimal level of capital taxation is determined by

$$
\tau=K \frac{F_{B}-1}{F_{B} \phi} .
$$

For any interior solution with $\tau>0$, overprovision or underprovision of the public service is determined by the sign of $\phi$. If $\phi>0$, then $F_{B}>1$ and the equilibrium is characterized by underprovision of business public services, as in the case of public services provided to residents analyzed by ZM. In contrast, if $\phi<0$, then $F_{B}<1$ and overprovision results. Note that from condition (13) $\phi=0$ is also a possibility, which implies $F_{B}=1$ and efficient provision of business public services.

Consider next a property that characterizes some production functions:

Property 2 The capital elasticity of the marginal productivity of the public service is smaller than 1 , or equivalently $F_{B}$ is an increasing and strictly concave function in $K$

$$
\varepsilon_{K, F_{B}}=\frac{K F_{B K}}{F_{B}}<1
$$

As shown in the appendix, Property 2 is crucial in allowing us to prove:

Proposition 1 Given properties 1 and 2, an interior solution with capital tax $\tau>0$ has the following properties: (1) $F_{B}>1$, that is, the business public service is underprovided, and (2) $\phi>0$, that is, each jurisdiction expects to drive out capital if it increases $\tau$. However, if property 2 is not satisfied, the capital tax equilibrium can lead to over-, efficient, or under-provision of the business public service.

This result can be related to the existing literature on the efficient provision of business public services. Matsumoto [13] notes (p.471): "If the number of firms is constant in each jurisdiction (normalized to one), [...] $\left[F_{B}\right]$ may be below one because the sign of $\left[F_{B}-K F_{K B}\right]$ is indeterminate under linear homogeneity with respect to all inputs. This argument corresponds to the 
Noiset [20] result of potential overprovision in the [ZM] model where the variability of the number of firms is not explicitly considered." Dhillon et al. [4] construct a model with two production inputs (capital and public services only), and assume Lemma 1 as do ZM in their paper. They develop alternative conditions that guarantee existence of a unique interior solution to the optimal capital tax, and then show that over-, efficient, or underprovision of the public service can occur depending on whether the production function is only locally or globally strictly concave in $(K, B)$. In the next section we introduce the concept of log (sub/super) modular production functions and show that both log submodularity and log modularity of $F(K, B)$ together with strict concavity in $(K, B)$ satisfy property $2 .^{11}$

\section{Production Tax}

Consider next the production tax scenario, in which case the government budget constraint is

$$
t F(K, B)=B
$$

Since firms receive the consumer price minus the tax for each unit of the consumption good sold, the income of residents is now given by (8) and the profit maximizing condition for capital is

$$
(1-t) F_{K}(K, B)=r
$$

In order to find the optimal production tax, we first need to evaluate the impact of capital and the production tax on the amount of the public service, $B$. Implicit differentiation of (16) yields

$$
\frac{\partial B}{\partial K}=\frac{t F_{K}}{\left(1-t F_{B}\right)},
$$

\footnotetext{
${ }^{11}$ Matsumoto [13] also notes that property 2 holds in the case in which $F(L, K, B)$ is linearly homogeneous in $(L, K)$. In this case

$$
F=F_{L} L+F_{K} K
$$

taking the derivative with respect to $B$

$$
F_{B}=F_{B L} L+F_{B K} K
$$

and given $F_{i j}>0$, implies $F_{B}>K F_{K B}$.
} 
and

$$
\frac{\partial B}{\partial t}=\frac{F}{\left(1-t F_{B}\right)} .
$$

Using (17) and the balanced budget constraint, the local government perceives an effect of an increase in $t$ on the capital stock given by

$$
\begin{aligned}
\frac{d K}{d t} & =\frac{F_{K}-(1-t) F_{K B} \frac{\partial B}{\partial t}}{(1-t)\left(F_{K K}+F_{K B} \frac{\partial B}{\partial K}\right)} \\
& =\frac{F_{K}\left(1-F_{B} t\right)-F_{K B} F(1-t)}{(1-t)\left(F_{K K}\left(1-F_{B} t\right)+F_{K B} F_{K} t\right)},
\end{aligned}
$$

where, as shown in the appendix, the denominator is unambiguously negative. $^{12}$ The marginal revenue of capital changes with an increase in the production tax in two ways: marginal productivity of capital goes up as the level of public service increases, but the higher tax rate reduces marginal revenue compared to the marginal revenue without the tax increase. The increase in marginal revenue is given by $(1-t) F_{K B} \frac{\partial B}{\partial t}$ and the decrease due to the tax increase is given by $-F_{K}$. Which of the two effects is larger in absolute value determines whether local jurisdictions perceive an outflow or inflow of capital.

The first order condition for the optimal production tax rate, found by maximizing (8) with respect to $t$, is 13

$$
F_{K} t\left(F_{K B} F-F_{B} F_{K}\right)-F_{K K} F\left(F_{B}-1\right)=0 .
$$

or

$$
t=\frac{K\left(-F_{K K}\right)\left(1-F_{B}\right)}{F_{B} F_{K}\left(\varepsilon_{K, F_{B}}-\varepsilon_{K}\right)},
$$

where $\varepsilon_{K, F_{B}}=F_{B K} K / F_{B}$ is the capital elasticity of the marginal productivity of the public service, and $\varepsilon_{K}=F_{K} K / F$ is the capital elasticity of production of the consumption good. With a positive production tax rate, underprovision (overprovision) of business public services occurs if $\varepsilon_{K B}<(>) \varepsilon_{K}$. The relative magnitudes of these two elasticities are determined by whether the production function can be characterized as log submodular or log supermodular in $(K, B)$. As shown in Smith [25], the production function $F(K, B)$ is

\footnotetext{
${ }^{12}$ As in the case of $\phi$ in the derivation in section 3.1, this result does not require property 2 .

${ }^{13}$ The derivation of the first order condition is found in the appendix.
} 
$\log$ submodular in $(K, B)$ if and only if

$$
\log F(K, B)+\log F\left(K^{\prime}, B^{\prime}\right)<\log F\left(K^{\prime}, B\right)+\log F\left(K, B^{\prime}\right)
$$

for all $K^{\prime}>K$ and $B^{\prime}>B$, while log supermodularity holds if the inequality is reversed. Intuitively, log supermodularity implies that an increase in the capital stock of a given size leads to a proportionately larger increase in output if the level of public services also increases. Analogously, log submodularity implies that an increase in the capital stock of a given size leads to a proportionally smaller increase in output if the level of public services also increases. In the appendix we show that for a twice differentiable function, $\log$ submodularity implies $F_{K B} F-F_{B} F_{K}<0$ or $\varepsilon_{K, F_{B}}<\varepsilon_{K}$, and log supermodularity implies $F_{K B} F-F_{B} F_{K}>0$ or $\varepsilon_{K, F_{B}}>\varepsilon_{K}$. In the knife-edge case of log modularity

$$
\log F(K, B)+\log F\left(K^{\prime}, B^{\prime}\right)=\log F\left(K^{\prime}, B\right)+\log F\left(K, B^{\prime}\right)
$$

for all $K^{\prime}>K$ and $B^{\prime}>B$, the corresponding conditions are $F_{K B} F=F_{B} F_{K}$, and $\varepsilon_{K, F_{B}}=\varepsilon_{K}$. These results imply

Proposition 2 A production tax is inefficient whenever the production function is log sub-or log supermodular in capital and the public service. Log submodularity (supermodularity) leads to underprovision (overprovision) of public services to firms. When a production function is log modular, a production tax is efficient.

Note that Proposition 2 does not depend on property 2. However, there is a relationship between log (sub)modularity and property 2 . In particular,

Lemma 2 If $F(K, B)$ is log (sub) modular and strictly concave in $(K, B)$, then property 2 holds.

The proof is provided in the appendix.

Note that the converse of Lemma 2 is not true; even if property 2 holds, no restriction is imposed on the log modularity property of $F(K, B)$.

Lemma 2 provides the starting point for our comparison between the welfare effects of a production tax and a capital tax. We provide this analysis in the next subsection. 


\section{Comparative Performance of the Capital Tax and the Production Tax}

Suppose the production function is log submodular and hence property 2 holds, so that both the optimal capital tax and the optimal production tax result in underprovision. In this case, we can unambiguously rank the two tax scenarios in terms of relative efficiency, as shown in

Proposition 3 Suppose that the production function is log submodular in $(K, B)$, and that interior solutions to both the optimal capital tax and the optimal production tax problems exist. Under these conditions, the production tax is unambiguously more efficient than the capital tax.

Proof Suppose the level of public services is the same under both tax regimes. That is,

$$
t F=\tau K=B,
$$

in which case total output is the same in all jurisdictions (given symmetry and a fixed national aggregate capital stock) and thus all derivatives are also identical. Multiplying the first order condition for each tax regime by its respective tax yields

$$
\begin{aligned}
\tau\left(F_{K B} B-F_{B} \tau\right)-F_{K K} B\left(F_{B}-1\right) & =0 \\
F_{K} t\left(F_{K B} B-F_{B} F_{K} t\right)-F_{K K} B\left(F_{B}-1\right) & =0 .
\end{aligned}
$$

Since both regimes lead to underprovision of public services, $-F_{K K} B\left(F_{B}-\right.$ 1) $>0$, and therefore the first terms in both (21) and (22) must be negative. We need to show that, given the optimal level of the public service under the capital tax equilibrium, the taxing jurisdiction would want to increase the production tax on a revenue neutral basis, which occurs if the first term in (22) is less negative than the first term in $(21) \cdot{ }^{14}$

$$
F_{K} t<\tau \text {. }
$$

Substituting from (20) this occurs if

$$
\begin{aligned}
F_{K} \frac{\tau K}{F} & <\tau \\
F_{K} K & <F
\end{aligned}
$$

\footnotetext{
${ }^{14}$ Recall that in order to obtain (22) we multiplied with two negative terms.
} 
which is the case since $F>F_{K} K$.

Note that this proof is valid even if there are multiple candidates for the optimal tax rates. The provision rule under each tax regime indicates how a jurisdiction should choose the optimal tax rate, given $K$. In the case in which the rule does not provide a unique tax rate, jurisdictions will choose the tax rate from all the candidates provided by the provision rule that leads to the highest residents' income, given $K$. Residents' income as a function of the public service level, which is calculated from the tax rate and, given $K$, is well-behaved and strictly concave in the public service level with its maximum at the efficient provision level of the public service. That is, the candidates for the optimal $\tau$ are chosen from

$$
\left(F_{K B} B-F_{B} \tau\right)-F_{K K} K\left(F_{B}-1\right)=0,
$$

which, after multiplying both sides by $K$, yields

$$
\left(F_{K B} B K-F_{B} B\right)-F_{K K} K^{2}\left(F_{B}-1\right)=0,
$$

and gives us the candidates for the optimal $B$ as a function of given $K$. The objective function in the case of capital taxation can be written as

$$
I_{C T}(B)=r \bar{K} / N+[F(K, B)-B-r K],
$$

where the $B$ argument indicates that the objective function is evaluated for a given value of $K$, and $B$ is selected from the candidates for the optimal capital tax. Hence the tax rates that we are evaluating are all associated with the same $K$. Then

$$
\begin{aligned}
\frac{\partial I(B)}{\partial B} & =F_{B}-1 \\
\frac{\partial^{2} I(B)}{\partial B^{2}} & =F_{B B}<0 .
\end{aligned}
$$

Hence the function $I_{C T}(B)$ is strictly concave in $B$, and in Proposition 3 we pick the $\tau$ that gives us the highest value for $I_{C T}(B)$ among all the $\tau^{\prime} s$ satisfying the optimality condition (21) .

Similarly, the objective function in case of taxation of production can be written as

$$
I_{P T}(t, K)=r \bar{K} / N+[(1-t) F(K, B)-r K],
$$


where we can calculate from the optimality condition for the production tax (22), given $K$, the corresponding $B$ by using $t F=B$. That is, we can rewrite 22 by multiplying the equation by $\frac{F}{t}$ to obtain

$$
F_{K} B\left(F_{K B} F-F_{B} F_{K}\right)-F_{K K} F^{2}\left(F_{B}-1\right)=0 .
$$

From this equation, we can find the candidates of the optimal $B$, as a function of $K$ and hence for given $K$

$$
\begin{aligned}
I_{P T}(B)=r \bar{K} / N+ & {[F(K, B)-B-r K] } \\
\frac{\partial I(B)}{\partial B} & =F_{B}-1 \\
\frac{\partial^{2} I(B)}{\partial B^{2}} & =F_{B B}<0 .
\end{aligned}
$$

Hence the function $I(B)$ is strictly concave in $B$, and in Proposition 3 we pick the $B$ that gives us the highest value for $I_{P T}(B)$ among all the $B^{\prime} s$ satisfying the optimality condition (22). However, this $B$ and its corresponding tax rate will not maximize the function $I_{P T}(B)$ in the case of log submodularity of the production function, as we know that both tax regimes lead to underprovision of the business public service since the taxing jurisdiction anticipates an outflow of capital in response to the imposition of the tax.

To compare the levels of underprovision under a capital tax and a production tax when the production function is log submodular, we can assume the jurisdiction has adopted the optimal capital tax and the corresponding level of public service, and then examine whether the jurisdiction would find it desirable to increase the level of public service provision using a production tax. We find that this is the case.

What is the interpretation of this result? It is true that by finding that the jurisdiction would increase the production tax at this point, we could be moving toward a suboptimal production tax rate. However, given the assumption that we have an interior solution under both tax regimes, the optimal production tax must be larger than any suboptimal production tax rate, so that switching to a production tax equilibrium increases the level of public service provided and results in less underprovision and thus less inefficiency than under the capital tax equilibrium.

Our results thus far validate the conjecture that a broad-based tax on local production is more efficient than a tax on capital in the case of log 
(sub)modular production functions. However, there is no analog to Proposition 3 in the case of log supermodular production functions, although there are prominent examples of such functions. In fact, the family of CES production functions includes examples of all three properties, depending on whether the elasticity of substitution between capital and public services/labor is greater than, equal to or smaller than one. In Gugl and Zodrow [7], we examine more closely this class of production functions in the context of tax competition in the provision of business public services and the relative efficiency of capital taxation and production taxation.

\section{Extensions}

In a recent paper, Matsumoto and Sugahara [17] consider a uniform input tax and find that such a tax can be efficient. In their model $F(L, K, B)$ is assumed to be CRS in $(L, K)$. Here we analyze such a uniform tax $\sigma$ on inputs in our model where $F(L, K, B)$ is CRS in $(L, K, B)$ and compare it to the performance of the tax on output. The budget constraint of the jurisdiction is

$$
\sigma(r K+w L)=B
$$

The objective function of a jurisdiction is

$$
I_{i T}=r \bar{K} / N+[F(K, \sigma(r K+w L))-((1+\sigma) r K+\sigma w L)]
$$

and the profit maximizing conditions for labor and capital, respectively of the representative firm are

$$
\begin{aligned}
& F_{L}(K, B)=(1+\sigma) w \\
& F_{K}(K, B)=(1+\sigma) r .
\end{aligned}
$$

Since labor is fixed, the wage rate will always lead to a demand of labour by the firm so that it equals the fixed labour supply. This means that $w$ will adjust with a change in the tax rate and this adjustment is taken into account by the local jurisdiction in determining the reaction of capital to an increase in $\sigma$. Substituting for $B=\sigma(r K+w L)$ in (24) and (25)and differentiating both equations with respect to $w, K$, and $\sigma$ and applying Crammer's rule we 
find

$$
\begin{aligned}
\frac{d K}{d \sigma}= & \frac{w F_{K B} \sigma L-F_{L B} \sigma L r+(1+\sigma)\left(r-F_{K B}(r K+w L)\right)}{D} \\
\frac{d w}{d \sigma}= & \frac{1}{D}\left[r\left(F_{L K}+F_{L B} \sigma r\right)+(r K+w L)\left(F_{K K} F_{L B}-F_{K B} F_{L K}\right)\right] \\
& -\frac{w\left(F_{K K}+F_{K B} \sigma r\right)}{D}
\end{aligned}
$$

where

$$
\begin{aligned}
D & =\left(F_{L K}+F_{L B} \sigma r\right) F_{K B} \sigma L-\left(F_{L B} \sigma L-(1+\sigma)\right)\left(F_{K K}+F_{K B} \sigma r\right) \\
& =F_{L K} F_{K B} \sigma L-F_{L B} \sigma L F_{K K}+(1+\sigma)\left(F_{K K}+F_{K B} \sigma r\right) .
\end{aligned}
$$

Provided $D \neq 0$, the first order condition for the local jurisdiction to set the uniform tax on inputs is

$F_{K} \frac{d K}{d \sigma}+F_{B}\left(r K+w L+\sigma r \frac{d K}{d \sigma}+\sigma L \frac{d L}{d \sigma}\right)-\left(r K+w L+\sigma L \frac{d w}{d \sigma}\right)-(1+\sigma) r \frac{d K}{d \sigma}=0$.

By (25) the first term and last term cancel each other out. Hence

$$
F_{B}\left(r K+w L+\sigma r \frac{d K}{d \sigma}+\sigma L \frac{d w}{d \sigma}\right)-\left(r K+w L+\sigma L \frac{d w}{d \sigma}\right)=0 .
$$

Proposition 4 The input tax leads to efficiency if there is no perceived reaction of capital to an increase in the uniform input tax.

Comparing the two terms in parantheses in (28) we need

$$
\sigma r \frac{d K}{d \sigma}+\sigma L \frac{d w}{d \sigma}=\sigma L \frac{d w}{d \sigma}
$$

for

$$
F_{B}=1
$$

Hence we must have

$$
\frac{d K}{d \sigma}=0 .
$$

In what follows we examine the case of a Cobb-Douglas production function. We know that the tax on output leads to efficiency because the Cobb-Douglas 
production function is log modular. Matsumoto and Sugahara [17] use a different model and find that a uniform tax on private inputs is efficient if the production function takes the Cobb-Douglas form and is CRS in private goods only. In this section, we show that, for a model similar to that constructed by Matsumoto and Sugahara, their efficiency result no longer holds when the CD production function is CRS in all inputs.

Let the production function be given by

$$
F(L, K, B)=L^{1-\kappa-\beta} K^{\kappa} B^{\beta}
$$

Analyzing the conditions necessary to lead to efficiency in the Cobb-Douglas case given CRS in all inputs, we find that the uniform tax on inputs is not efficient.

In the appendix we prove that the denominator in (26) and (27) is nonzero evaluated at $F_{B}=1$ for many parameter constellations if the production function is of the Cobb-Douglas type. If $\beta \geq \kappa$ the denominator is unambiguously negative. Using the functional form given in (29) the perceived reaction of capital as the uniform tax on input increases evaluated at $F_{B}=\beta \frac{F}{B}=1$ is given by

$$
\frac{d K}{d \sigma}=\frac{\left[-r((1-\kappa-\beta) \sigma+(1+\sigma) \kappa-(1+\sigma))-\left(\frac{\kappa}{1-\kappa-\beta} \frac{F}{K}\right)\right]}{D} .
$$

We would need

$$
\frac{d K}{d \sigma}=0
$$

By the profit maximization of firms with respect to $K$, we must have $\kappa \frac{F}{K}=$ $(1+\sigma) r$. Then

$$
\frac{d K}{d \sigma}=\frac{-r[((1-\kappa-\beta) \sigma+(1+\sigma) \kappa)(1-\kappa-\beta)+(1+\sigma)(\kappa+\beta)]}{D(1-\kappa-\beta)}
$$

So the numerator of $\frac{d K}{d \sigma}$ is negative when evaluated at $F_{B}=1$. Hence

$$
\frac{d K}{d \sigma} \neq 0
$$

This proves that a uniform tax on inputs in the case of a Cobb-Douglas function is not efficient for many parameter constellations. It leads the local jurisdiction to believe that a uniform rate increase at $F_{B}=1$ would lead to 
a change in capital so that the public service is not provided efficiently in equilibrium.

We conclude that Matsumoto and Sugahara's central result - that with a CD production function a uniform tax on inputs is efficient - does not carry over to the case in which the production function is CRS in all inputs.

\section{Conclusions}

Can a production tax, such as an origin-based value-added tax, approximate a benefit tax for public services provided to businesses, as suggested by Bird and others? And how does a source-based capital tax such as the property tax compare to a production tax as a proxy for a benefit tax? Using the Zodrow-Mieszkowski [32] model of interjurisdictional tax competition, we find that a production tax more closely approximates a benefit tax than does a capital tax in many instances. In particular, although a production tax is strictly efficient only when the production function is log modular in the public service and capital, it is less inefficient than a capital tax in the case of log submodular production technologies.

Our results may have some interesting implications for some potential reforms of state/provincial tax systems. In 2010, moving from a retail sales tax that was known to tax business inputs (due to problems in its administration) to a pure consumption tax in British Columbia spurred fierce opposition. While some of that opposition was sparked by the way the HST was introduced by the provincial government, critics of the HST also emphasized its shift away from "taxing business." The opposition was so forceful that continuation of the HST was the subject of a mail-in referendum, in which a majority of voters opposed the HST. As a result, British Columbia had to make the painful transition to re-establishing its provincial retail sales tax.

Our analysis suggests that a production tax may be a viable business tax alternative to the provincial retail sales tax, which is typically characterized by the taxation of business inputs similar to that which occurs under our capital tax. By comparison, at least under certain circumstances in our admittedly highly stylized model, a production tax is less distortionary than the capital tax portion of a retail sales tax. 


\section{Appendix}

\subsection{Proof of Lemma 1}

We show that

$$
F_{K K}+F_{K B} \tau<0 .
$$

Multiply (31) by $K$ to obtain

$$
F_{K K} K+F_{K B} \tau K
$$

Budget balance implies

$$
\tau K=B
$$

Hence

$$
F_{K K} K+F_{K B} \tau K \leq F_{K K} K+F_{K B} B .
$$

By property $1 F_{K K} K+F_{K B} B<0$, hence $F_{K K}+F_{K B} \tau<0$.

\subsection{Proof of Proposition 1}

Substituting for $\phi$ in (14) yields

$$
\tau=\frac{K F_{K K}\left(1-F_{B}\right)}{F_{B}-K F_{B K}}
$$

Note $K F_{K K}<0$. Then $\tau>0$ if and only if

$$
\begin{array}{ll}
\text { case } 1: & 1-F_{B}<0 \\
\text { case } 2: & 1-F_{B}>0
\end{array} \text { and } \quad \begin{aligned}
& F_{B}-K F_{K B}>0, \\
& F_{B}-K F_{K B}<0 .
\end{aligned}
$$

By property $2, F_{B}>K F_{K B}$. This means we are in case 1 , and $F_{B}>1$. Moreover by (14)

$$
F_{B}=\frac{K}{K-\tau \phi},
$$

which implies that $\phi>0$, concluding the proof.

Note that in the case in which taxes on residents or firms are imposed at an inefficiently low level, such that

$$
\tau K=B
$$

the same logic applies. Thus proposition 1 holds also if jurisdictions rely to some extent on these other taxes. 
Without property 2, case 2 is possible. From condition (13) it is also possible that $F_{B}=1$, and $\phi=0$. In this case the optimal $\tau$ is found by solving

$$
F_{B}=1
$$

\subsection{Denominator of $\frac{d K}{d t}$ is negative}

From (16) we know that $B=t F$. We need to sign

$$
\begin{aligned}
& \left(F_{K K}\left(1-F_{B} t\right)+F_{K B} F_{K} t\right) \\
= & \frac{1}{F}\left(F_{K K}\left(F-F_{B} t F\right)+F_{K B} F_{K} t F\right) \\
= & \frac{1}{F}\left(F_{K K}\left(F-F_{B} B\right)+F_{K B} B F_{K}\right) \\
= & \frac{1}{F K}\left(F_{K K} K\left(F-F_{B} B\right)+F_{K B} B F_{K} K\right) .
\end{aligned}
$$

By property $1,-F_{K K} K>F_{K B} B$. Strict concavity of $F(K, B)$ implies $F(L, K, B)>F_{B} B+F_{K} K$ and hence $F-F_{B} B>F_{K} K$. Thus $\left(F_{K K}\left(1-F_{B} t\right)+F_{K B} F_{K} t\right)<$ 0 .

\subsection{Proof of Proposition 2}

When the government chooses $t$ to maximize the income of residents, the FOC is

$-F+(1-t) F_{B} \frac{F}{1-F_{B} t}+\left(F_{B} \frac{F_{K} t}{1-F_{B} t}\right) \frac{F_{K}\left(1-F_{B} t\right)-F_{K B} F(1-t)}{\left(F_{K K}\left(1-F_{B} t\right)+F_{K B} F_{K} t\right)}=0$.

We now investigate the conditions for an interior solution with $1>t>0$. Note that $\left(1-F_{B} t\right)>0$, so we can multiply both sides of $(32)$ by this term. ${ }^{15}$ After collecting terms

$$
F\left(F_{B}-1\right)+F_{B} F_{K} t \frac{F_{K}\left(1-F_{B} t\right)-F_{K B} F(1-t)}{\left(F_{K K}\left(1-F_{B} t\right)+F_{K B} F_{K} t\right)}=0 .
$$

Note that an interior solution must have the following properties: If there is underprovision of public services, i.e. $F_{B}>1$, then the second term must

\footnotetext{
${ }^{15} F_{B} t=F_{B} \frac{B}{F}$. Since $F_{B} B<F,\left(1-F_{B} t\right)>0$.
} 
be negative and hence $\frac{d K}{d t}<0$. If there is overprovision, i.e. $F_{B}<1$, then the second term must be positive and hence $\frac{d K}{d t}>0$. If $t$ is efficient, $\frac{d K}{d t}=0$. At this point we cannot exclude any of these possibilities. The denominator of $\frac{d K}{d t}$ is negative, hence we can multiply both sides of (33) by this term to obtain

$$
\begin{aligned}
F\left(F_{B}-1\right)\left(F_{K K}\left(1-F_{B} t\right)+F_{K B} F_{K} t\right)+F_{B} F_{K} t\left(F_{K}\left(1-F_{B} t\right)-F_{K B} F(1-t)\right) & =0 \\
\left(F_{K K} F\left(F_{B}-1\right)+F_{B} F_{K} F_{K} t\right)\left(1-F_{B} t\right)+F_{K B} F_{K} t F\left(F_{B}-1\right)-F_{K B} F_{B} F_{K} t F(1-t) & =0 \\
\left(t F_{B}-1\right)\left(F_{K} t\left(F_{K B} F-F_{B} F_{K}\right)-F_{K K} F\left(F_{B}-1\right)\right) & =0 .
\end{aligned}
$$

Multiplying both sides with $t F_{B}-1<0$ yields

$$
F_{K} t\left(F_{K B} F-F_{B} F_{K}\right)-F_{K K} F\left(F_{B}-1\right)=0 .
$$

\subsubsection{Log Super- and Log Submodularity}

In this section we show that the property of log supermodularity implies $F_{K B} F-F_{B} F_{K}>0$, the property of $\log$ submodularity implies $F_{K B} F-$ $F_{B} F_{K}<0$, and the knife edge's case of log modularity (which falls between $\log$ super- and $\log$ submodularity) implies $F_{K B} F-F_{B} F_{K}=0$.

$F(L, K, B)$ is $\log$ supermodular if and only if

$$
F(L, K, B) F\left(L, K^{\prime}, B^{\prime}\right)>F\left(L, K^{\prime}, B\right) F\left(L, K, B^{\prime}\right)
$$

for all $K^{\prime}>K$ and $B^{\prime}>B$. Checking for log supermodularity using differentiation

$$
\frac{\partial F\left(L, K, B^{\prime}\right)}{\partial K} \frac{1}{F\left(L, K, B^{\prime}\right)}>\frac{\partial F(L, K, B)}{\partial K} \frac{1}{F(L, K, B)}
$$

if and only if $B^{\prime}>B .{ }^{16}$ With $F(\cdot)$ increasing, a necessary condition for this inequality to hold is $\frac{\partial F(L, K, B)}{\partial K \partial B}>0$. For sufficiency, the output elasticity of $K$ must be increasing with the increase in $B$ as (35) can be written as

$$
\frac{\partial F\left(L, K, B^{\prime}\right)}{\partial K} \frac{K}{F\left(L, K, B^{\prime}\right)}>\frac{\partial F(L, K, B)}{\partial K} \frac{K}{F(L, K, B)} .
$$

Let $\Phi(L, K, B)=\frac{\partial F(L, K, B)}{\partial K} \frac{1}{F(L, K, B)}$. Then if $F(L, K, B)$ is log supermodular, $\Phi(L, K, B)$ must be increasing in $B$. Thus take derivative wrt $B$ of $\Phi(K, B)$ :

$$
\frac{\partial \Phi}{\partial B}=\frac{1}{F} F_{K B}-F_{K} \frac{F_{B}}{F^{2}}>0 .
$$

\footnotetext{
${ }^{16}$ See, e.g., Smith [25].
} 
This inequality can be rewritten

$$
F_{K B} F-F_{K} F_{B}>0 \text {. }
$$

Therefore the efficiency condition under a production tax depends on whether $F(L, K, B)$ is log supermodular or log submodular in $(K, B)$. Log submodularity corresponds to underprovision, log supermodularity to overprovision, and the knife-edge case of log modularity corresponds to efficiency.

\subsection{Proof of Lemma 2}

Log (sub) modularity requires

$$
F_{K B} F-F_{K} F_{B} \leq 0 .
$$

Rearranging and multiplying by $K$

$$
\frac{F_{K B} K}{F_{B}} \leq \frac{F_{K} K}{F} .
$$

By strict concavity of $F$ in $(K, B)$

$$
F_{K} K<F
$$

Hence

$$
\frac{F_{K B} K}{F_{B}}<1 .
$$

Rearranging yields the desired result

$$
F_{B}-F_{K B} K>0 \text {. }
$$

\subsection{Proof that $D$ in section 6 is negative}

In general,

$$
D=F_{L K} F_{K B} \sigma L-F_{L B} \sigma L F_{K K}+(1+\sigma)\left(F_{K K}+F_{K B} \sigma r\right) .
$$

In the special case of the Cobb-Douglas production function

$$
\begin{aligned}
D= & (1-\kappa-\beta) \kappa \frac{F}{L K} \kappa \beta \frac{F}{B K} \sigma L-(1-\kappa-\beta) \beta \frac{F}{L B} \sigma L(\kappa-1) \kappa \frac{F}{K K} \\
& +(1+\sigma)\left((\kappa-1) \kappa \frac{F}{K K}+\kappa \beta \frac{F}{B K} \sigma r\right) .
\end{aligned}
$$


Dividing by $\kappa \frac{F}{K}$

$$
\begin{aligned}
\frac{K D}{\kappa F}= & (1-\kappa-\beta) \kappa \beta \frac{F}{B K} \sigma-(1-\kappa-\beta) \beta \frac{F}{B K} \sigma(\kappa-1) \\
& +(1+\sigma)\left((\kappa-1) \frac{1}{K}+\beta \frac{1}{B} \sigma r\right) .
\end{aligned}
$$

Simplifying

$$
\frac{K D}{\kappa F}=(1-\kappa-\beta) \beta \frac{F}{B K} \sigma+(1+\sigma)(\kappa-1) \frac{1}{K}+\beta \frac{1}{B} \sigma(1+\sigma) r .
$$

Since

$$
\begin{gathered}
F_{K}=\kappa \frac{F}{K}=(1+\sigma) r \\
\frac{K D}{\kappa F}=(1-\beta) \beta \frac{F}{B K} \sigma+(1+\sigma)(\kappa-1) \frac{1}{K} .
\end{gathered}
$$

At

$$
\begin{gathered}
F_{B}=\beta \frac{F}{B}=1 \\
\frac{K D}{\kappa F}=\frac{(1-\beta) \sigma+(\kappa-1)+\sigma(\kappa-1)}{K} \\
=\frac{(\kappa-1)+\sigma(\kappa-\beta)}{K} .
\end{gathered}
$$

Note that this leads to a positive or negative sign for many parameter constellations. It is necessarily negative with $\kappa \leq \beta$.

\section{References}

[1] Bird, Richard M. (2002), "Subnational VATs: Experience and Prospects," Proceedings of the Annual Conference on Taxation of the National Tax Association, National Tax Association, Washington, DC.

[2] Bayindir-Upmann, Thorsten (1998), "Two Games of Interjurisdictional Competition When Local Governments Provide Industrial Public Goods," International Tax and Public Finance 5: 471-487. 
[3] CBC News (2011), "B.C. promises HST cut to $10 \%$ by 2014: Tax hike for corporations and cheques for families also promised" posted May 25, 2011, http://www.cbc.ca/news/canada/britishcolumbia/story/2011/05/25/bc-hst-changes.html

[4] Dhillon, Amrita, Myrna Wooders and Ben Zissimos (2007), "Tax Competition Reconsidered," Journal of Public Economic Theory 9: 391-423.

[5] Feehan, James P. and Mutsumi Matsumoto (2000), "Productivityenhancing public investment and benefit taxation: the case of factoraugmenting public inputs," Canadian Journal of Economics 33: 114121.

[6] Gramlich, Edward M.(1993), "Infrastructure Investment: A Review Essay," Journal of Economic Literature 32: 1176-1196.

[7] Gugl, Elisabeth and George R. Zodrow (forthcoming), "Competition in business taxes and public services: are production-based taxes superior to capital taxes?" National Tax Journal.

[8] Haufler, Andreas and Michael Pflüger (2007), "International Oligopoly and the Taxation of Commerce with Revenue-Constrained Governments." Economica 74: 451-73.

[9] Hines, James R. Jr. (2002), "Michigan's Flirtation with the Single Business Tax." Working paper. Office of Tax Policy Research, University of Michigan, Ann Arbor, MI.

[10] Kanbur, Ravi and Michael Keen (1993). "Jeux sans frontiers: tax competition and tax coordination when countries differ in size," American Economic Review 83: 877-92.

[11] Keen, Michael and Maurice Marchand (1997), "Fiscal Competition and the Pattern of Public Spending," Journal of Public Economics 66: 3353.

[12] Lockwood, Ben (2001). "Tax competition and tax co-ordination under destination and origin principles: a synthesis," Journal of Public Economics 81: 279-319. 
[13] Matsumoto, Mutsumi (1998), "A Note on Tax Competition and Public Input Provision," Regional Science and Urban Economics 28: 465-473.

[14] Matsumoto, Mutsumi (2000a), "A Tax Competition Analysis of Congestible Public Inputs," Journal of Urban Economics 48: 242-259.

[15] Matsumoto, Mutsumi (2000b), "A Note on the Composition of Public Expenditure under Capital Tax Competition," International Tax and Public Finance 7: 691-697.

[16] Matsumoto, Mutsumi and James P. Feehan (2010),"Capital-tax financing and scale economies in public-input production," Regional Science and Urban Economics 40:116-121.

[17] Matsumoto, Mutsumi and Kota Sugahara (2014), "Factor Taxation and Public Input Provision under Tax Competition - A Note" Discussion Paper No 2014-01, Graduate School of Economics, Kyoto Sangyo University.

[18] McLure, Charles E. (2003), "The value added tax on electronic commerce in the European Union," International Tax and Public Finance 10: $753-62$.

[19] Mintz, Jack M. and Henry Tulkens (1986), "Commodity tax competition between member states of a federation: equilibrium and efficiency," Journal of Public Economics 29, 133-72.

[20] Noiset, Luc (1995), "Pigou, Tibout, Property Taxation, and the Underprovision of Local Public goods: A Comment," Journal of Urban Economics 38: 312-316.

[21] Oates, Wallace E. and Robert M. Schwab (1988), "Economic Competition Among Jurisdictions: Efficiency Enhancing or Distortion Inducing?" Journal of Public Economics 35: 333-354.

[22] Oates, Wallace E. and Robert M. Schwab. "The Allocative and Distributive Implications of Local Fiscal Competition," in Daphne A. Kenyon and John Kincaid (eds.) Competition among States and Local Governments: Efficiency and Equity in American Federalism, The Urban Institute Press, 1991, chapter seven. 
[23] Richter, Wolfram F. (1994), "The Efficient Allocation of Local Public Factors in Tiebout's Tradition," Regional Science and Urban Economics 24: 323-340.

[24] Sinn, Hans-Werner (1997), "The Selection Principle and Market Failure in Systems of Competition," Journal of Public Economics 66: 247-274.

[25] Smith, Lones (2006), "The Marriage Model with Search Frictions," Journal of Political Economy 114: 1124-1144.

[26] Tiebout, Charles (1956), "A Pure Theory of Local Expenditures," The Journal of Political Economy 64: 416-424.

[27] Wilson, John D. (1986), "A Theory of Interregional Tax Competition," Journal of Urban Economics 19: 296-315.

[28] Wilson, John D. (1999), "Theories of Tax Competition," National Tax Journal 52: 269-304.

[29] Wilson, John D. and David E. Wildasin (2004), "Tax Competition: Bane or Boon?" Journal of Public Economics 88: 1065-1091.

[30] Zodrow, George R. (2003), "Tax Competition and Tax Coorodination in the European Union." International Tax and Public Finance 10: 651671.

[31] Zodrow, George R. (2010),"Capital Mobility and Capital Tax Competition," National Tax Journal 63 (4): 865-901.

[32] Zodrow, George R. and Peter Mieszkowski (1986), "Pigou, Tiebout, Property Taxation and the Underprovision of Local Public Goods," Journal of Urban Economics 19: 356-70. 